\title{
A IMPORTÂNCIA DO LAYOUT PARA AS EMPRESAS
}

\section{THE IMPORTANCE OF LAYOUT FOR BUSINESS}

\author{
André Luiz Vieira Santos - andre84luiz@gmail.com \\ Ramilio Ramalho Reis Filho - ramilio.ramalho@ hotmail.com \\ Faculdade de Tecnologia de Taquaritinga (FATEC) -SP -Brasil
}

DOI: 10.31510/infa.v16i2.677

\section{RESUMO}

As organizações estão inseridas em um mercado competitivo, que não têm espaço para empresas que não possuem uma harmonia interna dos seus colaboradores, máquinas e ferramentas, o objetivo deste trabalho é pesquisar e confirmar os benefícios que o layout pode trazer internamente à empresa ou indústria, além de aumentar a produtividade e controle sobre os processos existentes. A metodologia utilizada foi de caráter bibliográfico e um levantamento de publicações do tema, com o objetivo de comprovar a relevância do tema estudado, para professores, alunos e empresas que necessitam de uma ferramenta de melhoria contínua com um custo reduzido. O resultado da metodologia escolhida demonstra a eficiência e eficácia do layout como ferramenta nas organizações, quando alinhados com as características da empresa e quando elaborado para atender as necessidades produtivas e competitivas da empresa.

Palavras-chave: Layout. Arranjo Físico. Melhoria Contínua. Benefícios. Vantagens e Desvantagens.

\begin{abstract}
Organizations are inserted in a competitive market, which has no space for companies that do not have an internal harmony of their employees, cachines and tools, the objective of this paper is to research and confirm the benefits that layout can bring internally to the company or industry, as well as increase productivity and control over existing processes. The methodology used was bibliographic and a survey of publications of the theme, with the objective of proving the relevance of the studied theme, for teachers, students and companies that need a continuous improvement tool with a reduced cost. The result of the chosen methodology demonstrates the efficiency and effectiveness of layout as a tool in organizations, when aligned with company characteristics and when designed to meet the productive and competitive needs of the company.
\end{abstract}

Keywords: Layout. Physical Arrangement. Continuous Improvement. Benefits. Advantages and Disadvantages. 


\section{INTRODUÇÃO}

Entender e compreender os benefícios que um layout bem desenhado de acordo com as necessidades da organização traz para a empresa e se faz necessário, uma vez que o mesmo pode ser um fator determinante para o aumento de produtividade, redução de desperdícios de tempo e melhorando a ergonomia dentro da organização, então um layout bem definido, têm se tornado um objetivo a ser alcançado, pelas empresas que querem aumentar sua produtividade e reduzir o tempo desperdiçado.

Neste artigo serão abordados, alguns tópicos relevantes, sobre a importância do layout e quais os benefícios que pode trazer para uma empresa, sobretudo identificar as metodologias utilizadas para a criação de um layout, apresentando argumentos que possam levar as organizações uma mudança em seus arranjos físicos.

O objetivo deste trabalho é descrever a importância do layout dentro das organizações, incentivando-as a se adaptarem e reformularem sua forma de trabalho, para que se consiga obter o máximo de desempenho de suas máquinas, funcionários, ferramentas e materiais.

Por ser comprovado a sua eficiência e eficácia no meio industrial, o layout é uma das ferramentas mais utilizadas para que haja um aumento na produtividade, e por sua flexibilidade ao adaptar-se à realidade de qualquer empresa, que deseje aumentar a sua produtividade, reduzir o tempo ocioso e aumentar o desempenho em todas as áreas na empresa.

O layout, ou como também é chamado, arranjo físico, segundo Chiavenato (2005), pode ser caracterizado como a forma de distribuição de máquinas e equipamentos no interior da organização, adequado diretamente ao produto confeccionado, para que o trabalho dos funcionários seja desenvolvido eficientemente e com o menor desperdício de tempo.

Já o autor Araújo (2010), descreve o layout como fator de equilíbrio entre as pessoas, máquinas, ferramentas e materiais em uma organização, equilíbrio esse, encontrado através da viabilização e planejamento do layout de acordo com as necessidades da empresa.

Segundo Peinado e Reis (2007, p.200), ao falar da importância do layout, descrevem que:

As decisões do arranjo físico definem como a empresa vai produzir. O layout, ou arranjo físico, é a parte mais visível e exteriorizada da empresa. A necessidade do estudo sobre o assunto existe sempre que se pretende a implementação de uma nova fábrica ou unidade de serviço, e até mesmo se estiver acontecendo um planejamento, para a reformulação de uma nova planta industrial. 
Devido a sua importância e necessidade dentro das organizações; o layout possibilita uma melhor visualização dos processos de uma organização, aumentando a produtividade no menor tempo possível, tornando-se a melhor opção para a empresa que deseja um aumento da produtividade sem necessitar de um alto investimento. Este artigo tem relevância por abordar um tema funcional, e que se implementado de maneira correta é de extrema eficiência e eficácia.

\section{FUNDAMENTAÇÃO TEÓRICA}

Corrêa e Corrêa (2012) afirmam que layout é uma mudança física dos recursos de transformação que envolve o espaço de áreas industriais e administrativas em uma organização, essa mudança resulta em modificações relevantes nos procedimentos ou nos fluxos físicos, para que ambos estejam em paralelo com as características ideais do layout e as prioridades competitivas das empresas.

É perceptível a partir da definição acima, que o arranjo físico é de um valor imensurável para toda e qualquer empresa, uma vez que aplicado, adequado as necessidades da empresa e funcionando, o layout pode trazer uma melhor performance para a empresa nas diversas áreas que à compõe.

Muito mais do que melhorar a performance da empresa, o layout reflete nas decisões operacionais mais amplas, apto a fornecer vários benefícios, por envolver não só a estética do ambiente, mais também promover a melhoria operacional, a ergonomia, e o bem-estar das pessoas que estão atuando no ambiente organizacional. (ANTONIOLLI, 2009).

O layout pode ser considerado como a maneira na qual se encontram distribuídos fisicamente os recursos que ocupam espaço dentro de uma instalação, uma vez que podem se tratar de recursos transformados ou transformadores. Os recursos transformados sendo matéria prima, informações e clientes, e os recursos transformadores sendo as máquinas, equipamentos e operadores (MOREIRA, 2008).

\subsection{Tipos/Modelos de Layout}

Segundo Martins et al. (2006) existem três tipos de modelos de layout, são eles: funcional, em linha e celular. 


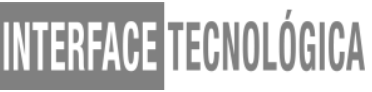

Segundo Corrêa e Corrêa (2012), afirmam que são quatro tipos de layout existentes, sendo eles: posicional, por processo, celular ou por produto. Afirmam então que qualquer empresa tem seu layout inicial, fundamentado em um desses quatro tipos.

\subsubsection{Layout Funcional ou Processo}

De acordo com Martins et al.(2006) todos os processos e equipamentos são planejados e criados na mesma área, assim como também são agrupadas as montagens e operações semelhantes no mesmo local. O material é que se desloca pelo processo. É um tipo de layout bem flexível que se adapta as mudanças do mercado e do espaço físico, visando atender produtos diversificados e com uma demanda também variável ao longo do tempo.

\subsubsection{Layout Linear ou Produto}

Martins et al.(2006) afirma que nesse layout todos os processos são colocados de forma sequencial, de acordo com as operações, sem desvio ou possibilidade de caminhos alternativos, ou seja, uma vez que o caminho é pré-determinado o produto/serviço não pode alterar sua rota. Indicado para produções com nenhuma diversidade de produtos, com uma quantidade constante ao decorrer do tempo ou uma grande quantidade desse mesmo produto. Requer um alto investimento no maquinário da empresa e pode apresentar erros na qualidade do produto. Podendo gerar estresse e LER (Lesão por Esforço Repetitivo) aos funcionários devido a monotonia do processo.

\subsubsection{Layout Celular}

Baseado em arranjar um só local (uma célula), buscando máquinas diferenciadas que fabriquem o produto do início ao fim. O material se movimenta dentro da célula, a fim de passar por todos os processos necessários. É flexível quanto o tamanho do lote por produto eleva ao nível de qualidade e produtividade, apesar de atender apenas alguns produtos específicos, diminuindo o transporte desnecessário de material e estoque. (MARTINS et al., 2006) 


\subsubsection{Layout Fixo}

O arranjo físico por posição fixa é considerado por Slack et al. (2009) como um tanto quanto contraditório, uma vez que os recursos transformados não se movem entre os recursos transformadores, ou seja, ao invés de materiais, informações ou clientes fluírem por uma operação, quem sofre o processamento fica parado, enquanto os recursos transformadores se movem na medida do necessário.

\subsubsection{Layout Combinado}

A utilização de layouts combinados, segundo Martins e Laugeni (2015) ocorre para aproveitar em um determinando processo as vantagens do layout funcional e da linha de montagem.

\subsubsection{Processo de escolha do Layout}

A definição de um layout ideal para a empresa está ligado diretamente com o planejamento que observa e qual o modelo que tem mais afinidade com o produto ou serviço que será realizado pela empresa. Dessa forma os autores Slack, Chambers e Jonhston. (2009), desenvolveram um modelo, apresentado na ilustração 1, que liga as características, o volume e a variedade de produtos desejados, com cada um dos modelos de layout descritos.

Ilustração 1 - Modelo de Volume-Variedade

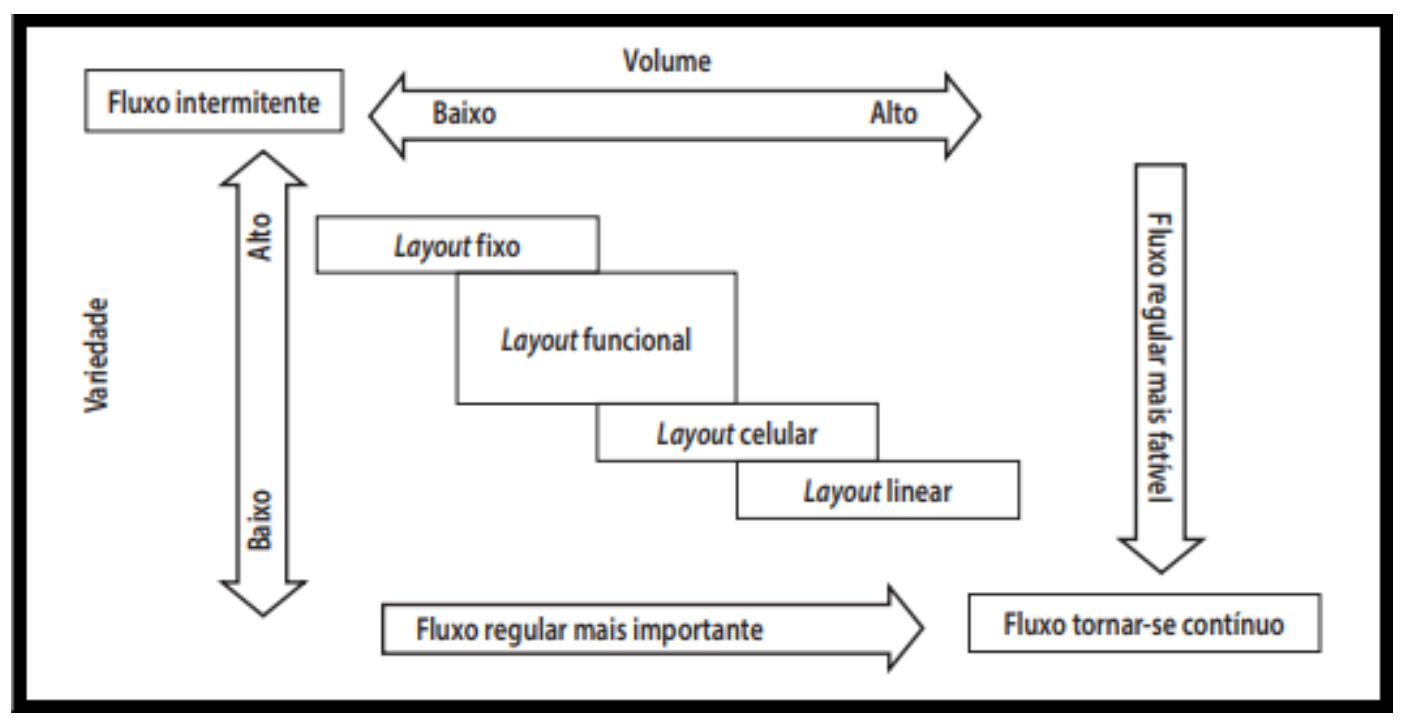

Fonte: Elaborado por Slack, Chambers e Jonhston. (2007). 
Para desenvolver um projeto de layout que atenda às necessidades de uma empresa, é preciso compreender os tipos básicos de layouts existentes que, segundo Martins e Laugeni (2015),são layout por processo, layout em linha, layout celular, layout por posição fixa e layout misto ou combinado, como podemos observar abaixo no quadro 1.

Quadro 1 - Modelos de Layout

\begin{tabular}{|c|l|l|}
\hline Modelo & \multicolumn{1}{|c|}{ Definição } & \multicolumn{1}{|c|}{ Objetivo } \\
\hline $\begin{array}{c}\text { Linear Ou } \\
\text { Produto }\end{array}$ & $\begin{array}{l}\text { Máquinas posicionadas de acordo } \\
\text { com a sequencia de montagem dos } \\
\text { produtos. }\end{array}$ & Proporcionar alta produtividade. \\
\hline Funcional Ou Processo & $\begin{array}{l}\text { Caracterizado por máquinas com } \\
\text { mesma funçăo săo agrupadas. }\end{array}$ & $\begin{array}{l}\text { Minimizar custos com o fluxo de } \\
\text { produtos e recursos no processo. }\end{array}$ \\
\hline Celular & $\begin{array}{l}\text { Máquinas, processos e măo de obra } \\
\text { no mesmo local. }\end{array}$ & $\begin{array}{l}\text { Localizar os recursos } \\
\text { transformadores de acordo com a } \\
\text { melhor conveniência. }\end{array}$ \\
\hline Fixo & $\begin{array}{l}\text { Produto permanece no mesmo } \\
\text { local e os recursos e operaçōes se } \\
\text { deslocam ao seu redor. }\end{array}$ & $\begin{array}{l}\text { Melhorar a eficiência dos recursos } \\
\text { transformadores. }\end{array}$ \\
\hline Hibrido, Combinado Ou Misto & $\begin{array}{l}\text { Combina as características de dois } \\
\text { ou mais modelos citados acima. }\end{array}$ & $\begin{array}{l}\text { Consiliar os processos, produtos } \\
\text { e máquinas de acordo com as } \\
\text { caracteristicas dos diferentes } \\
\text { modelos. }\end{array}$ \\
\hline
\end{tabular}

Fonte: Elaborado por Peinado e Graeml (2007).

Quadro 2 - Vantagens e desvantagens dos modelos de layout

\begin{tabular}{|c|c|c|}
\hline Modelo & Vantagens & Desvantagens \\
\hline Linear & $\begin{array}{l}\text { - baixos custos unitários para altos volumes } \\
\text { de produção; } \\
\text { - baixa quantidade de estoques de produtos } \\
\text { em processamento; } \\
\text { - movimentação adequada de materiais. }\end{array}$ & $\begin{array}{l}\text { - baixa flexibilidade de mix; } \\
\text { - trabalho repetitivo, prejudicando a moral e } \\
\text { motivação dos colaboradores; } \\
\text { - alta dependência entre as atividades, sendo } \\
\text { que a falha em uma etapa pode afetar todo } \\
\text { o processo. }\end{array}$ \\
\hline Funcional & $\begin{array}{l}\text { - alta flexibilidade de mix e produto; } \\
\text { - fácil supervisão de equipamentos e } \\
\text { instalaçōes; } \\
\text { - facilidade no treinamento, visto que há } \\
\text { menor quantidade de funçōes. }\end{array}$ & $\begin{array}{l}\text { - baixa utilizaçăo de recuros, maior } \\
\text { osciosidade; } \\
\text { - maior estoque em processo; } \\
\text { - menor velocidade de movimentaçăo; } \\
\text { - maior número de setup. }\end{array}$ \\
\hline Celular & $\begin{array}{l}\text { - trabalho em grupo incentva motivação; } \\
\text { - equilibrio entre custo e flexibilidade para } \\
\text { operaçōes com alta variedade; } \\
\text { - maior facilidade no planejamento e } \\
\text { controle da produção. }\end{array}$ & $\begin{array}{l}\text { - possivel dificuldade de adaptaçăo } \\
\text { dos operadores pela alta variedade de } \\
\text { atividades; } \\
\text { - alto custo para reconfigurar o arranjo; } \\
\text { - reduz niveis de utilizaçăo de recursos. }\end{array}$ \\
\hline Fixo & $\begin{array}{l}\text { - flexibilidade muito alta de mix e produto; } \\
\text { - alta variedade de tarefas para a máo de } \\
\text { obra; } \\
\text { - produto ou cliente não movido. }\end{array}$ & $\begin{array}{l}\text { - custos unitários muito altos; } \\
\text { - programação de atividade ou espaço pode } \\
\text { ser complexa; } \\
\text { - pode exigir muita movimentação de } \\
\text { máquinas e mão de obra. }\end{array}$ \\
\hline
\end{tabular}

Fonte: Elaborado por Rosa et al. (2014). 


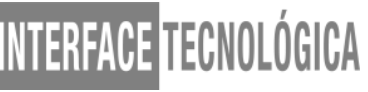

No quadro 2 acima vemos as vantagens e desvantagens dos modelos de layouts.

\subsection{A importância de se Adotar um Layout bem Definido}

Peinado e Graeml (2007) acreditam que o que leva a empresa a uma mudança em seu layout, surge da necessidade de expandir a produtividade, diminuição dos custos operacionais, necessidade de uma nova variedade de produtos e a melhoria do espaço de trabalho.

De acordo com Peinado e Graeml (2007), o layout traz benefícios ligados à segurança dentro da organização, uma vez que através do arranjo físico, é possível pré-estabelecer, os locais de riscos e as pessoas que terão acesso a esses locais, além de identificar através dele as saídas de emergência, tornando imprescindível a sua adoção no espaço de trabalho.

Segundo a EJEP (2017) um planejamento eficaz de um layout é importante por trazer vários benefícios, sendo eles:

- Melhoria do fluxo interno de pessoas

- Otimização do espaço utilizado pela empresa

- Bom controle e gerenciamento das atividades

- Minimização de desperdícios de tempo

- Redução de custos

- Minimização da inatividade de máquinas.

A importância de se implementar ou aperfeiçoar o espaço físico da empresa, vai além da redução de custos e aumento de produtividade dos processos. Um layout ira refletir nos passos mais importantes, dados pela empresa, oferecendo vantagens e benefícios para a empresa, ao englobar a aparência no espaço físico, trazer melhorias operacionais e melhorar o desempenho dos funcionários. (ANTONIOLLI, 2009).

\section{PROCEDIMENTOS METODOLÓGICOS}

Para o desenvolvimento deste artigo, foram utilizadas duas técnicas de pesquisa, a bibliográfica e a de campo, a fim de compor a estrutura teórica e conseguir obter dados para comprovação da importância do tema. 
Segundo Marconi e Lakatos (2011, p.57), afirmam que:

A pesquisa bibliográfica, ou de fontes secundárias, abrange toda a bibliografia já tornada pública, em relação, ao tema de estudo, desde publicações avulsas, boletins, jornais, revistas, livros, pesquisas, monografias, teses, material cartográfico etc., até meios de comunicação orais: rádio, gravações em fita e áudio visuais: filmes, televisão e internet. Com o objetivo de colocar o pesquisador em contato direto com tudo o que foi escrito, dito ou filmado sobre o tema de estudo, inclusive conferências seguidas de debates que tenham sido transcritos por alguma forma, ou publicadas ou gravadas.

Já a pesquisa de campo, tem como objetivo a obtenção de informações e conhecimentos, em volta de um tema de estudo, no qual objetiva-se a procura de uma resposta ou de fortalecer uma hipótese que se queira comprovar, ou ainda, descobrir novas relações entre eles. (MARCONI E LAKATOS, 2011).

Neste trabalho a pesquisa de campo foi utilizada, através de um levantamento de dados, sobre o número de artigos publicados nos sites da ENEGEP e SCIELO nos últimos anos, relacionados ao tema de estudo do artigo, a fim da comprovação da relevância do layout nas organizações.

\subsection{Parâmetros e Critérios para a Obtenção de Dados}

Nesta etapa, após a definição das técnicas utilizadas para compor o artigo, foi estabelecido parâmetro e critérios, para a obtenção de dados e para gerar resultados. Os dados obtidos, devem obrigatoriamente seguir os padrões pré-estabelecidos.

\section{Quadro 2 - Parâmetros e Critérios}

\begin{tabular}{|c|c|}
\hline Tema & Layout / Arranjo físico \\
\hline Palavras - Chaves & $\begin{array}{c}\text { Layout; arranjo físico; layout e produtividade; importância do } \\
\text { layout; mais produtividade, redução de custos; aparência } \\
\text { organizacional; otimização do espaço etc. }\end{array}$ \\
\hline Tipos de documentos & Artigos acadêmicos publicados nos últimos 4 anos \\
\hline Sites & ENEGEP e SCIELO
\end{tabular}

Fonte: Elaboração própria (2019). 


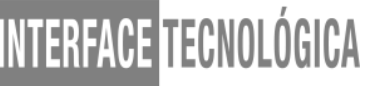

Apesar de ser um tema bem discutido por muitos, e com bastantes referências teóricas, o grande número de palavras-chaves é para que se consiga o maior número de dados possíveis nos sites citados, visando uma melhor visualização dos resultados.

Ilustração 2 - Interface de busca no sistema ENEGEP

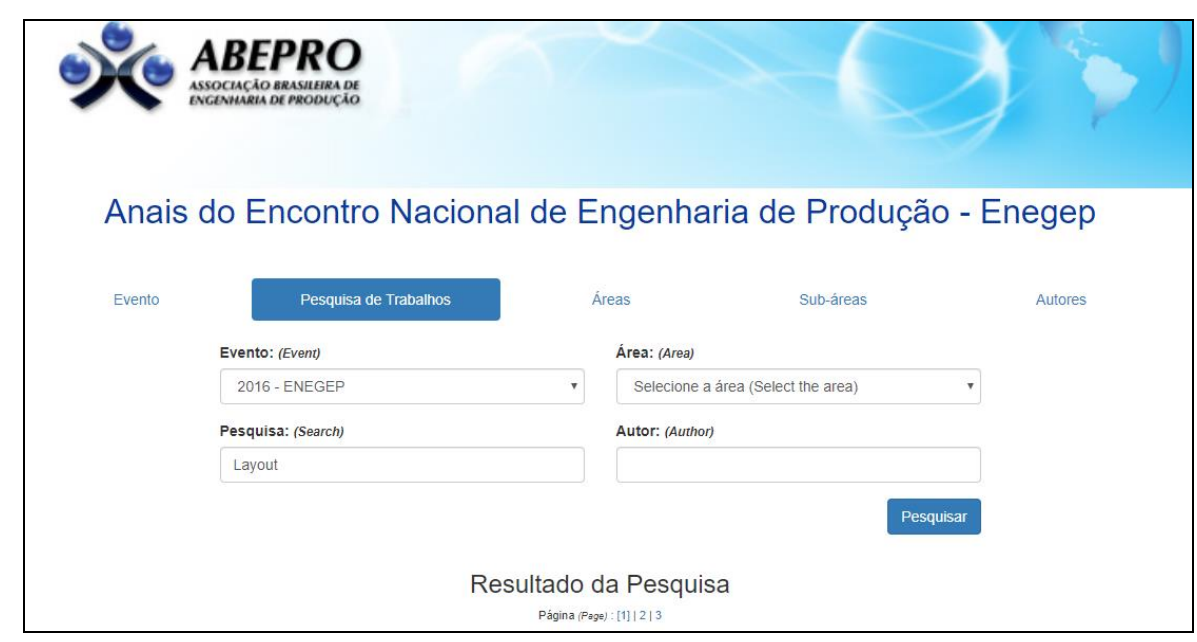

Fonte: Ilustração tirada do site da ABEPRO (2019).

$\mathrm{Na}$ ilustração 2 é possível identificar os meios, no qual pode-se realizar as pesquisas no site, as buscas foram a partir das palavras chaves e do ano de publicação.

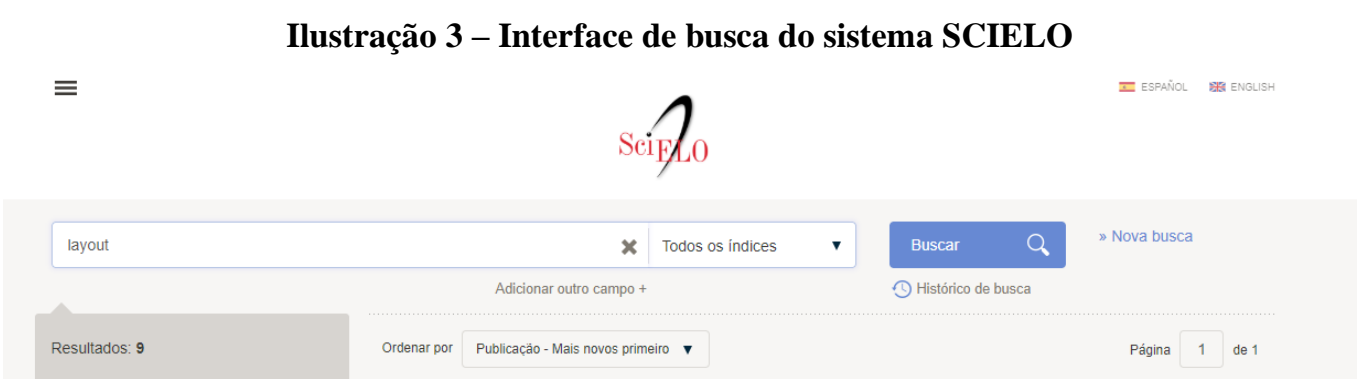

Fonte: Ilustração tirada do site SCIELO (2019).

$\mathrm{Na}$ ilustração 3 nota-se que o site da SCIELO, possibilita adicionar filtros para conseguir uma avanço maior nas pesquisas.

\section{RESULTADOS E DISCUSSÃO}

Nesta etapa, após a coleta de dados, foi realizada uma comparação do número de artigos publicados em dois sites, bibliotecas online mais renomadas da área de tecnologia de produção, para identificar qual a relevância do tema de estudo nos últimos quatro anos, e 
comprovar que o layout é um dos assuntos de estudo mais visados quando falamos da área de produção industrial como demonstrado na tabela 1.

Tabela 1 - Planilha de dados obtidos através das buscas.

\begin{tabular}{|c|c|c|}
\hline \multicolumn{1}{|c|}{ ANO } & \multicolumn{1}{c}{ ENEGEP } & \multicolumn{1}{c|}{ SCIELO } \\
\hline 2015 & 21 & 10 \\
\hline 2016 & 38 & 16 \\
\hline 2017 & 45 & 20 \\
\hline 2018 & 26 & 14 \\
\hline TOTAL & 130 & 60 \\
\hline
\end{tabular}

Fonte: Elaboração própria (2019).

Na tabela 1 mostrada acima, é possível notar que se realizarmos a somatória dos artigos da ENEGEP e da SCIELO nos últimos quatro anos, chega a 190 publicações, o que mostra ainda uma grande relevância do tema para os profissionais e estudantes da área de Produção Industrial.

Ilustração 4 - Gráfico comparativo.

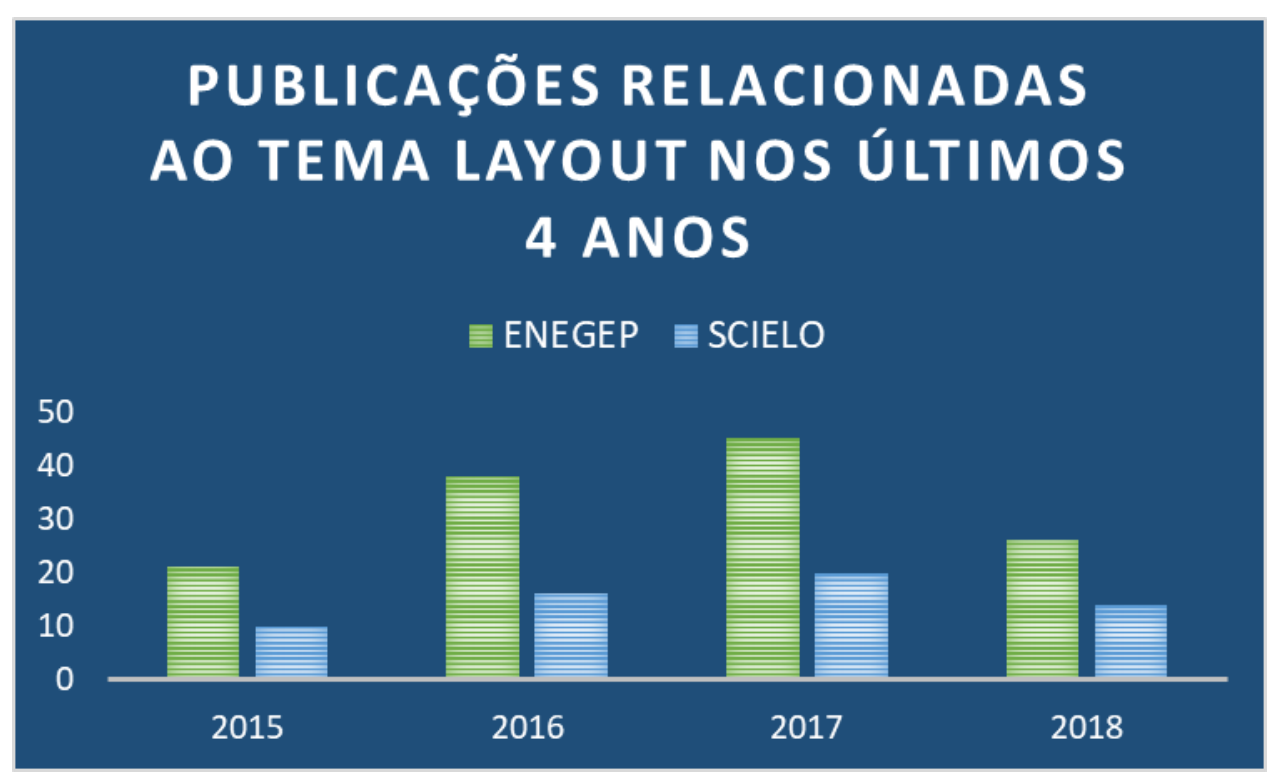

Fonte: Elaboração Própria (2019). 


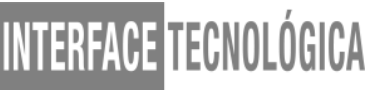

Ao analisar o gráfico acima, pode se notar um número bem maior de artigos publicados nos anos de 2016 e 2017 em relação ao anos de 2015 e 2018, mesmo que seja perceptível que houve uma queda considerável no número de publicações, ainda assim os gráficos apontam que muitas pessoas ainda buscam estudar o tema apresentado, pela sua necessidade e benefícios que pode trazer à empresa, que adota layouts bem definidos.

\section{CONCLUSÃO}

O layout é de extrema importância para as indústrias, empresas e organizações em geral, uma vez que, se os maquinários, ferramentas, operadores, encarregados, e área administrativa não atuarem em harmonia e em volta de um mesmo objetivo, é o mesmo que decretar falência, então o layout tem como objetivos, planejar, organizar, controlar e ajudar a dirigir todos os processos internos da empresa.

O objetivo deste trabalho foi demonstrar através de fontes teóricas, a eficiência e eficácia do layout, bem como, os tipos, qual escolher, as vantagens e desvantagens, e a importância do mesmo para as empresas que desejam um processo produtivo menos vulnerável, com diminuição de gargalos, resolução dos problemas na logística entre outros.

O foco foi buscar um tema de estudo, que apresente uma melhoria contínua, para as empresas que adotem um layout bem definido, proporcionando uma melhor visualização e identificar quais os principais problemas que podem atrapalhar a produtividade. Além de buscar incentivar os profissionais, professores e estudantes a pesquisarem e colocarem em prática as vantagens do layout como uma ferramenta, que apresenta reais resultados.

Ou seja, as considerações finais sobre o tema de estudo, é que o layout ainda é um tema muito visado pelas indústrias, por ter um custo reduzido, comparado a outras ferramentas de melhoria contínua, sendo eficaz para reduzir muitas falhas e problemas dentro do processo produtivo, de logística e administrativa dentro das organizações.

\section{REFERÊNCIAS}

\section{ANTONIOLLI, S. Proposta de Otimização de Fluxo em um Setor de Produção com} Arranjo Funcional. Joinville: 2009. Disponível em: <https://www.passeidireto.com/arquivo/11055274/2009_2_tcc04>. Acesso em: 27 de ago. 2019. 
ARAÚJO, L. C. G. Organização, Sistemas e Métodos e as Tecnologias de Gestão Organizacional: arquitetura, benchmarking, empowerment, gestão pela qualidade total e reengenharia. 4. ed. São Paulo: Atlas, 2010.

CORRÊA, H. L.; CORRÊA, C. A. Administração de Produção e de Operações: manufatura e serviços: uma abordagem estratégica. São Paulo: Atlas, 2012.

CHIAVENATO, I. Gestão de Pessoas. 2. ed. Rio de Janeiro: Elsevier, 2005.

EJEP. A Importância de um Layout Bem Planejado. Florianópolis: EJEP, 11 maio 2017. Disponível em:< http://ejep.com.br/2017/05/11/a-importancia-de-um-layout-bem-planejado>. Acesso em: 27 de ago. 2019.

MARCONI, M. A.; LAKATOS, E. M. Metodologia do Trabalho Científico: procedimentos básicos, pesquisa bibliográfica, projeto e relatório, publicações e trabalhos científicos. 7. ed. 6. reimpr. São Paulo: Atlas: 2011.

MARTINS, P. G. et al. Administração da Produção. 2. ed. São Paulo: Saraiva, 2006.

MARTINS, P. G.; LAUGENI, F. P. Administração da Produção. 3. ed. São Paulo: Saraiva, 2015.

MOREIRA, D. A. Administração da Produção e Operações. 2. ed. São Paulo: Cengage Learning, 2008.

PEINADO, J.; GRAEML, A. R. Administração da Produção: operações industriais e de serviços. Curitiba: UnicenP, 2007.

PEINADO, J.; REIS, A. G. Administração da Produção: operações industriais e de serviços. Curitiba: UnicenP, 2007.

ROSA, G. P. et al. A Reorganização do Layout Como Estratégia de Otimização da Produção. Bauru: GEPROS, 2014. Disponível em:

<https://revista.feb.unesp.br/index.php/gepros/article/viewFile/1126/583>. Acesso em: 27 de ago. 2019.

SLACK, N.; CHAMBERS, S.; JOHNSTON, R. Administração da Produção. 3. ed. São Paulo: Atlas, 2009. 